\title{
Medicinal plants used in treatment of inflammatory skin diseases
}

\author{
Renata Dawid-Pać
}

Department of Medicinal and Cosmetics Natural Products, Poznan University of Medical Sciences, Poland Head: Prof. Gerard Nowak MD, PhD

Postep Derm Alergol 2013; XXX, 3: 170-177

DOI: 10.5114/pdia.2013.35620

\begin{abstract}
Skin is an organ providing contact with the environment and protecting the human body from unfavourable external factors. Skin inflammation, reflected adversely in its functioning and appearance, also unfavourably affects the psyche, the condition of which is important during treatment of chronic skin diseases. The use of plants in treatment of inflammatory skin diseases results from their influence on different stages of inflammation. The paper presents results of the study regarding the anti-inflammatory activity of the plant raw material related to its influence on skin. The mechanism of action, therapeutic indications and side effects of medicinal plants used for treatment of inflammatory diseases of the skin are described.
\end{abstract}

Key words: inflammation of the skin, atopic dermatitis, plant drugs, anti-inflammatory activity.

\section{Introduction}

Skin is the most extensive and diverse organ of the human body. General skin condition is important not only for the aesthetic reasons, but also because of health. Its unfavourable look resulting from dermatitis affects the psychic condition of the patient, and both these factors play an important role in development and treatment of chronic skin diseases [1].

Inflammation is provoked by pathogens, noxious mechanical and chemical agents, and autoimmune responses, and it is a complex process during which the body repairs tissue damage and defends itself against harmful stimuli. Inflammation is characterized by such symptoms as redness, swelling, itching, heat, and pain [2]. Under the influence of an inflammatory factor, some intracellular biochemical substances are released from cells. Monocytes and macrophages produce cytokines (regulatory glycoproteins of the immunological system). The basic role of cytokines in inflammatory processes is, inter alia, to activate cells involved in the inflammation (neutrophils, macrophages, and mast cells), enable communication between them, induce the prostaglandin synthesis and affect the synthesis of the C-reactive proteins. Among cytokines one can distinguish pro-inflammatory (interleukins IL-1, IL-6, IL-8, IL-17, IL-18, $\alpha$ and $\beta$ interferon, and the tumour necrosis factor - TNF) and anti-inflammatory ones (e.g. IL-4, IL-10, IL-13). Predominance of the first type leads to the systemic inflammatory reaction whereas predominance of anti-inflammatory cytokines results in the anti-inflammatory response [3].

Regulation of the inflammatory processes and cellular response also involves eicosanoids: prostaglandins (PGD, PGE, and PGF), prostacyclins (PGI), thromboxanes (TXA), leukotrienes (LTB, LTC, LTD), mediators arising as a response to stimuli from the arachidonic acid (AA) connected with the cell membrane in the form of phospholipids [4].

Chronic inflammatory diseases emerge as a response to the disorders of inflammatory processes and excessive production of pro-inflammatory mediators such as IL-1 $\beta$, $\mathrm{IL}-6, \mathrm{TNF}-\alpha$ and $\mathrm{PGE}$, initiating an inflammatory reaction cascade. In addition, in the course of skin inflammatory diseases one can observe disturbance of the biosynthesis of eicosanoids in epidermis and instability of the neuroimmunological system in the skin, i.e. increased production of neurological mediators such as P substance which stimulates synthesis of the nitrogen oxide $[5,6]$.

One of the typical inflammation-based diseases is atopic dermatitis (atopic eczema), which is a chronic disease affecting people genetically inclined to overreact to external factors. The most frequently observed symptoms of atopic dermatitis are excessive skin dryness and itching, exfoliation,

Address for correspondence: Renata Dawid-Pać Pharm. D., Department of Medicinal and Cosmetics Natural Products, Poznan University of Medical Sciences, 33 Mazowiecka St, 60-623 Poznan, Poland, phone: +48 618480475 , fax: +48 61 847 0628 , e-mail: reniadp@ump.edu.pl

Received: 4.10.2012, accepted: 10.02.2013. 
redness, skin irritation, exudations, swelling of the affected skin areas, spots, rash, and blisters with watery secretion. Staphylococcus aureus is being observed to colonize skin. The origin of atopic dermatitis is very complex and its causes are not fully recognized as yet. It is claimed that during the onset and in the course of the disease, the most important are the genetic factors and influence of the external environment [7-9].

An immunological mechanism which plays an important role in the pathogenesis of atopic dermatitis and other skin diseases of the inflammatory origin, is related to activation of T lymphocytes and it is a result of complex interactions of different cells: keratinocytes, endothelium cells, eosinophils, Langerhans cells and T lymphocytes, and also many cytokines and mediators. In atopic skin diseases, atopic dermatitis and psoriasis, skin cells produce interleukins initiating inflammatory reactions [10]. In patients, excessive production of specific antigens lgE against low doses of food and inhalant allergens, which are responsible for the development of the inflammation, is observed. As a result of releasing the leukotrienes, prostaglandins and proteases, inflammation symptoms occur in different organs and systems. Excessive skin dryness, characteristic of atopic dermatitis, is related to the change of activity of $\Delta 6$-desaturase - an enzyme catalysing transformation of the linolenic acid into the $\gamma$-linolenic one. Patients affected with this disease display a low level of essential fatty acids (EFA) and disorder of lipid production in epidermis, which are of significance during formation and persistence of dermal changes. In patients suffering from atopic dermatitis, an increased value of TEWL (in dry skin areas and not affected by inflammation, and the clinically healthy skin) is observed, which may be related to a lowered concentration of lipids in skin, especially that of ceramides, and the loss of ingredients of a natural moisturizing factor - NMF [11-14]. In treatment of atopic dermatitis, plant raw materials with anti-inflammatory properties and ability to regulate the synthesis of lipids in epidermis are utilized. The most important among them, demonstrating both mechanisms of action, is an internally applied oenothera oil. Raw materials applied externally during treatment of atopic dermatitis, effectiveness of which results from their antiinflammatory activity, are camomile head, hamamelis water, hamamelis leaves and St John's wort.

The paper presents results of the study regarding the anti-inflammatory activity of the plant raw material related to its influence on the skin. Medicinal plants used in treatment of dermatitis, atopic dermatitis, eczema, furunculosis and other inflammatory diseases of the skin are described.

\section{Matricariae flos = Chamomillae anthodium - matricaria flower}

Matricaria recutita L. (German chamomile) is the most known and commonly used medicinal plant. It has flower heads with white internal linguiform flowers and the exter- nal tubular - yellow, typical of the Asteraceae family. It contains the essential oil (the major components of which are $\alpha$-bisabolol and its oxides A, B and C, matricin, which is converted to chamazulene by distillation and en-yndicycloethers) and flavone derivatives: apigenin, luteolin, and apigenin-7-glucoside [15].

Extracts of matricaria flower exhibited anti-inflammatory activity by inhibition of prostaglandins and leukotrienes synthesis in vitro. $\alpha$-Bisabolol and apigenin inhibited cyclooxygenase and 5-lipooxygenase activity, chamazulene inhibited only 5-lipooxygenase [16]. A dry extract of matricaria flower, applied locally, inhibited croton oil-induced oedema in vivo, comparably to benzydamine (anti-inflammatory synthetic drug) [15]. Intradermal application of liposomal apigenin7-glucoside inhibited skin inflammations induced in rats. Topical application of either the total chamomile extract or the flavonoid fraction only was very effective in reducing inflammation in a mouse model for croton oil-induced dermatitis. Apigenin and luteolin were more active than indometacin and phenylbutazone (non-steroidal anti-inflammatory synthetic drugs). Activity decreased in the following order: apigenin, luteolin, quercetin, myricetin, apigenin-7-glucoside, rutin [17].

In the pharmacological study in humans, ointment containing matricaria flower extract was more effective than $0.1 \%$ hydrocortisone (anti-inflammatory synthetic drug) in reduced chemically-induced toxic dermatitis. Creams containing matricaria flower extract reduced UV-induced erythema [15]. In clinical studies, anti-inflammatory activity of ointment containing matricaria flower extract (treatment of patients suffering from inflammatory dermatoses on hands, forearms and lower legs) was comparable to that of $0.25 \%$ hydrocortisone, and superior to $0.75 \%$ fluocortin butyl ester and 5\% bufexamac (nonsteroidal anti-inflammatory synthetic drugs) [18]. In another clinical study, after 2 weeks of treatment of patients with medium-degree atopic eczema, effectiveness of creams containing matricaria flower extract was superior to that of $0.5 \%$ hydrocortisone cream with respect to the symptoms of pruritus, erythema and desquamation [15].

The essential oil of chamomile and $\alpha$-bisabolol demonstrated bactericidal and fungicidal activity in vitro (mainly against Gram-positive bacteria, Staphylococcus aureus, Bacillus subtilis and fungi Candida albicans) [17, 19].

Matricaria flower is externally used for skin inflammations and irritations, bacterial skin diseases, nappy rash and cradle cap, eczema, wounds (infected and poorly healing), abscesses, frostbite, and insect bites $[1,17,18]$. Matricaria flower is used for baths, compresses or rinses and poultice $[15,18]$. Rare cases of contact allergy have been reported [15].

\section{Calendulae flos - calendula flower}

Calendula officinalis L (marigold) is native to the Mediterranean countries. It has characteristic yellow-orange flower heads. Active ingredients of the calendula flower are triterpene saponins (oleanolic acid glycosides), triter- 
pene alcohols ( $\alpha$-, $\beta$-amyrins, faradiol), and flavonoids (quercetin and isorhamnetin) [20-22]

Anti-inflammatory effects of Calendulae flos are related to the content of flavonoids and triterpene derivatives. Isorhamnetin 3-glycosides isolated from calendula flowers inhibited lipoxygenase. Oleanane-type triterpene glycosides exhibited a marked anti-inflammatory activity in the TPA-induced inflammation in the mouse ear [20, 21]. Calendulae flos extract, the main components of which are triterpenoids, applied topically, inhibited the croton oilinduced oedema in vivo. The activity of this extract (at high concentration) and faradiol was comparable to that of indometacin (anti-inflammatory synthetic drug) [20-22].

Calendula flower is used for compresses in poorly healing wounds, bruises, rashes, boils and dermatitis. Application in children under 6 years of age is not recommended [20].

\section{Hamamelidis cortex - hamamelis bark}

Hamamelis virginiana $\mathrm{L}$. (witch hazel) is a high shrub, or a small tree, native to North America. It has characteristic, light yellow flowers, which appear in autumn, with convolute or straight band-shape petals [23]. Active ingredients of hamamelis bark are tannins - hamamelitannins and proanthocyanidins, which in vitro strongly inhibit 5-lipoxygenase activity, synthesis of leukotriene B4, and proanthocyanidins only inhibit synthesis of PAF (platelet activating factor) $[24,25]$. A hydro-ethanolic extract of hamamelis bark, applied topically, showed anti-inflammatory effect in the croton oil oedema test in mice. This effect was shown to be mainly due to proanthocyanidins molecular weight $\geq 3 \mathrm{kDa}$ (69\% inhibition) and hamamelitannins (7\% inhibition); proanthocyanidins of lower molecular weight $<3 \mathrm{kDa}$ had no effect [26].

Decoctions and infusions of hamamelis bark are used for local inflammation of the skin [24]. The use in children under 12 years of age is not recommended [26].

\section{Hamamelidis folium - hamamelis leaf}

The characteristic constituents of hamamelis leaf are tannins - proanthocyanidins and small amount of hamamelitannins. In clinical research, creams containing hamamelidis folium extract were effective in treatment of atopic eczema in children, atopic xeroderma and other eczemas.

In all cases, inflammation symptoms subsided [27]. Decoctions of hamamelis leaf are used for compresses or washes in treatment of local inflammations of the skin [27]. The use in children under 6 years of age is not recommended [26].

\section{Hamamelidis aqua = folium et cortex aut ramunculus destillatum hamamelis water $=$ hamamelis distillate}

Hamamelidis aqua contains a volatile oil, the major components of which are aliphatic hydrocarbons, monoterpenes, sesquiterpenes, aliphatic aldehydes and alcohols. Hamamelis water displays the anti-inflammatory activity [28]. In pharmacological studies in humans, the after sun lotion containing $10 \%$ of hamamelis water reduced the UV-B-induced erythema. The lotion containing Hamamelidis suppressed erythema by $20 \%$ at $7 \mathrm{~h}$ and by $27 \%$ at $48 \mathrm{~h}$, whereas the degree of suppression seen with the Hamamelidis-free lotions was $11 \%$ and $15 \%$, respectively $[25,28]$. In a clinical trial, 72 patients suffering from severe atopic eczema were treated with two ointments: a cream containing hamamelis distillate ( $25 \mathrm{~g} / 100 \mathrm{~g})$ and bufexamac ( $50 \mathrm{mg} / \mathrm{g}$ ) - anti-inflammatory and anti-pruritic synthetic drug. Reduction symptoms such as desquamation of the skin, redness, itching and lichenification was shown. No differences were observed in the global assessment of the therapy or the severity of symptoms between ointments. The cream containing 0.5\% hydrocortisone was more potent than the cream containing hamamelis distillate $(5.35 \%)$ in the symptomatic treatment of patients with moderately severe atopic eczema $[25,28]$.

Hamamelis water is used undiluted or diluted $1: 3$ with water, for compresses, in treatment of minor inflammations and irritations of the skin such as cuts, grazes, insect bites and burns $[26,28]$. Application in children under 6 years of age is not recommended [26].

\section{Aloe vera folium recens - aloe fresh leaf (fresh leaves of Aloe vera)}

Aloe barbadensis Mill. syn. A. vera (L) Burm. f. (Barbados aloe, cape aloe) is a succulent with bright yellow tubular flowers and thick and fleshy, 30-50 cm long, pea-green leaves (spotted with white when young). The leaf edge is jagged and spiny [29]. Active ingredients in fresh leaves of Aloe vera are carbohydrates (mannose-6-phosphate, acemannan - acetylated1,4 polymer of mannose), glycoproteins, sterols (lupeol, $\beta$-sitosterol) and enzymes (bradykinase). Gel is prepared from fresh leaves and it is an antranoid-free preparation [19, 29-31].

Fresh Aloe Vera Gel significantly reduced acute inflammation in rats (carrageenin-induced paw oedema), although no effect on chronic inflammation was observed. Enzymes, carbohydrates and sterols contribute to anti-inflammatory activity of the aloe gel. Bradykinase inhibited thromboxane $\mathrm{B}_{2}$ and prostaglandin $\mathrm{F}_{2}$ activity in vitro, and mannose- 6 phosphate, acemannan and sterols (mainly lupeol) reduced inflammation induced experimentally in vivo [29, 32, 33]. Aloe Vera Gel is used for external treatment of minor wounds and inflammatory skin disorders, minor skin irritations including burns, bruises, and abrasions. The use of freshly prepared gel is recommended because of its sensitivity to enzymatic, oxidative or microbial degradation. Rare cases of contact allergy have been reported [29].

\section{Althaeae radix - marshmallow root}

Althaea officinalis L. (marshmallow) is native to Europe and is now cultivated in Poland. It has characteristic big 
leaves, similar to maple-tree leaves, with a sharp apex and indented edge [23]. Active compounds are mucilage polysaccharides - arabinogalactans, galacturonorhamnans, glucans and arabinans. The extract of the marshmallow root stimulates phagocytosis and the release of oxygen radicals and leukotrienes from human neutrophils. Release of cytokines: interleukin-6 and tumour necrosis factor (TNF), from monocytes, by the extracts, demonstrated their potential anti-inflammatory activity [34, 35].

An ointment containing an aqueous marshmallow root extract (20\%) reduced irritation induced by UV radiation or tetrahydrofurfuryl alcohol in vivo. The anti-inflammatory effect was weaker than that of an ointment containing dexamethasone $0.05 \%$ (anti-inflammatory synthetic drug), but an ointment containing both active ingredients has higher anti-inflammatory activity than ointments containing individual active ingredients [34]. Marshmallow root is externally used for furunculosis, eczema and dermatitis [36].

\section{Avenae fructus - oat fruit}

Avena sativa L. (oat) is native to the warm Mediterranean region. It is cultivated in moderate regions of Europe, Asia and North America for its yield of grain. It has characteristic inflorescence - a composite panicle, unlike rye, wheat and barley [37]. Active constituents of oat fruit are mucilage polysaccharides ( $\beta$-glucan), proteins (glutelin and avenin), and flavonoids [6].

In vitro, a colloidal extract of Avena sativa showed antiinflammatory activity - inhibited liberation of the arachidonic acid from phospholipids and the subsequent metabolism into prostaglandin and leukotrienes. Also, it inhibited the expression of phospholipase $\mathrm{A}_{2}\left(\mathrm{PLA}_{2}\right)$ and cyclooxygenase (COX-2) [5]. A colloidal extract of Avena sativa stimulated production of the anti-inflammatory transforming growth factor $\beta 1$ (TGF $\beta 1$ ) by keratinocytes and inhibited production of interleukins [10]. In a pharmacological trial, 20 and $30 \%$ colloidal extracts of oat (in Petrolatum), under occlusion for $2 \mathrm{~h}$, protected the skin from irritation induced by sodium lauryl sulfate which caused redness of the skin and increased the cutaneous blood flow (improvement of both parameters was observed) [6]. Colloidal oatmeal was applied to 11 patients with rash induced by drugs administered during treatment. Out of 10 patients assessed, 6 showed a complete response and 4 - partial response, with no toxic effects observed [6].

Avenae fructus is a traditional, herbal medicinal product for the symptomatic treatment of minor skin inflammations (such as sunburn), and it is used as an aid in the healing of minor wounds. Skin reactions may occur in atopic patients and in patients with contact dermatitis [6].

\section{Avenae stramentum - oat straw}

Oat straw contains polysaccharides ( $\beta$-glucan) and silicon dioxide in a soluble form - as esters of the silicic acid with polyphenols, and monosaccharides and oligosaccharides. In vitro and in vivo, $\beta$-glucan stimulates immune functions. Silicon regulates skin and subcutaneous metabolic processes. Oat straw is used for inflammatory and seborrheic skin diseases, especially those accompanied by itching [1, 37].

\section{Echinaceae purpureae herba recens - purple coneflower fresh herb}

Echinacea purpurea (L.) Moench (purple coneflower) is a United States native plant; in Europe and Asia it is grown as an ornamental plant because of its big flower heads with purple flowers which gave the name to the species [23]. Purple coneflower fresh herb contains alkamides and caffeic acid derivatives (mainly cichoric, caftaric and chlorogenic acids) [38, 39].

Echinacea extracts, standardized for the caffeic acid derivatives, have been shown to display in vitro an antiinflammatory activity consisting in inhibition of prostaglandin $E_{2}\left(P G E_{2}\right)$ synthesis [40]. In vitro, E. purpurea alkamides inhibited activity of the COX-I and COX-II enzymes [38]. Echinacea is a traditional, herbal, medicinal product applied for treatment of small superficial wounds and inflammation of the skin. Externally, expressed juice or dried expressed juice is used [38, 39, 41]. Hypersensitive reactions (local rash, contact dermatitis, eczema and angioedema of the lips) are possible, and allergic reactions may occur in patients with atopic diseases [38]. The use of this medicinal product for more than 8 weeks and in children below 12 years of age is not recommended [38, 39].

\section{Symphyti radix - comfrey root}

Symphytum officinale L. (comfrey) is common in Poland throughout the country. It grows up to $50-100 \mathrm{~cm}$, has rough, hairy leaves and large, usually purple-red (sometimes white) flowers which form drepanium-type inflorescence $[1,19]$. Active constituents of comfrey root are the amine compound (allantoin), phenolic acids (rosmarinic, salicylic and caffeic acid), mucilage polysaccharides and glycopeptides [42]

In vitro, rosmarinic acid and glycopeptides isolated from comfrey root have been shown to possess the antiinflammatory activity. Rosmarinic acid inhibits synthesis of the prostaglandins, and glycopeptides, dose-dependently, inhibit release of the prostaglandins ( $P G E_{2}$ and $\left.P G I_{2}\right)$, and also of 12-HETE and the arachidonic acid. In pharmacological studies in healthy humans, dermatological preparations containing $5 \%$ or $10 \%$ of comfrey root extract were effective in reducing UV-B-induced erythema. Anti-inflammatory potency of the extracts was comparable, or even greater than that of diclofenac (non-steroidal anti-inflammatory synthetic drug). A positive correlation could be demonstrated between the efficacy and the concentration of the caffeic acid [42]. 
Comfrey root is used in treatment of skin inflammation and leg ulcerations. It is not used internally because of its pyrrolizidine alkaloid content which shows hepatotoxic, carcinogenic, and mutagenic properties in rats. For the same reason, external use of comfrey should be limited to phytopharmaceutical products with standardized pyrrolizidine alkaloid content. Application for not more than 4-6 weeks per year is recommended, and a daily application should contain from $10 \mu \mathrm{g}$ to $100 \mu \mathrm{g}$ pyrrolizidine alkaloids $[1,19,42]$.

\section{Millefolii herba - yarrow}

Achillea millefolium L.s.l. (yarrow) is native to Europe, Asia and North America. The plant is characterised by small, white flowers, gathered in inflorescences and multiple complex leaves (divided into many segments), which gave the name of the species [43]. Millefolii herba contains essential oil (the major components of which are sesquiterpenes of the guaianolide type (chamazulene), $\alpha$-, $\beta$-pinene, tannins (condensed and hydrolysable), sesquiterpene lactones (matricine), and flavonoids (luteolin, apigenin, isorhamnetin, rutin) [44].

Yarrow displays anti-inflammatory and astringent properties. In vitro, a water-soluble fraction from a hydroalcoholic extract showed anti-inflammatory activity, chamazulene inhibited leukotriene $\mathrm{B}_{4}\left(\mathrm{LTB}_{4}\right)$ production by inhibition of 5-lipoxygenase. Millefolii herba extracts, examined in vivo, showed anti-inflammatory properties related to the content of flavonoids and sesquiterpene lactones in the raw material $[43,44]$.

Yarrow is used in supportive treatment of small wounds and mild inflammations of the skin. Because of the sesquiterpene lactone content, cases of allergic contact dermatitis may occur [44].

\section{Plantaginis lanceolatae folium/herba - ribwort plantain leaf/herb}

Plantago lanceolata L. (ribwort plantain) is a perennial plant. It has numerous, lancet-shaped leaves forming a rose and tiny flowers gathered into a ball or eggshaped blossom of the ear type [23]. Active ingredients are phenylethanoids (acteoside, plantamajoside), mucilage polysaccharides, iridoids (aucubin and catalpol) and tannins $[45,46]$.

The material has astringent properties related to the presence of tannins, emollient and soothing properties due to the content of mucus and anti-inflammatory properties (conditioned - inter alia - by phenylethanoids) [45]. In vitro, extracts of the plantain herb inhibited inflammation. This activity was comparable to that of hydrocortisone, phenylbutazone and diclofenac. In vitro and in vivo, acteoside and plantamajoside had anti-inflammatory activity - they inhibited 5-lipooxygenase, and acteoside inhibited production of 5-HETE and leukotriene $B_{4}$. In vivo, both compounds applied topically inhibited arachidonic acid-induced mouse ear oedema (acteoside was less active than plantamajoside) [46].

The macerate of ribwort plantain leaf/herb is used for cataplasms and rinse in supportive therapy of poorly healing wounds and skin inflammation [45].

\section{Salviae folium - sage leaf}

Salvia officinalis L (sage) is native to the Mediterranean region. It is cultivated in Europe, also in Poland. The whole plant is grey, hairy and has a strong, camphoric aroma [23]. Sage leaf contains phenolic acids (rosmarinic acid), triterpenoids acids (ursolic and oleanolic acid), essentials oil (monoterpenes) and catechin-type tannins (salviatannin) [47-49].

Sage leaf has astringent, bactericidal and anti-inflammatory properties. Ursolic and rosmarinic acids have been shown to possess anti-inflammatory activity in vitro and in vivo. In vivo, extracts from sage leaf dose-dependently inhibited croton oil-induced ear oedema in mice. This effect is related to the content of the ursolic acid which in this test had the potency twice as high as that of indometacin. Oleanolic acid also exhibited anti-inflammatory activity but it was less active $[47,49]$. In vitro, sage oil showed bactericidal (tested on Gram-positive and Gramnegative bacteria) and fungicidal properties [49].

Sage leaf is a traditional, herbal medicinal product for relief of minor skin inflammations and bacterial infections of the skin. The use in children and adolescents under 18 years of age and during pregnancy and lactation is not recommended because the available data on possible effects are insufficient [48].

\section{Hyperici herba - St. John's wort}

Hypericum perforatum L. can be found in Asia, North America, Africa and Europe; it is very popular in Poland. Its generic name is derived from transparent spots on leaves, containing oil tanks [23]. The characteristic compounds are phloroglucinol derivates (mainly hyperforin and adhyperforin), naphtodianthrones (hypericin) and flavonoids (amentoflavone, hyperoside) [50,51].

In vivo, extracts from Hyperici herba and pure compounds exhibited anti-inflammatory activity proved by reduction of croton-oil-induced ear oedema in mice - the most potent compound was the lipophilic extract. Pure compounds had anti-inflammatory activity that was more potent or comparable to that of indometacin [50]. In vitro, hypericin inhibited the protein kinase $C$ activity and release of the arachidonic acid and leukotriene $B_{4}\left(L_{T B}\right)$ [51]. Hyperforin (in vitro), and also the extract from St. John's wort containing hyperforin and an ointment based on a 1: 9 alcoholic extract of this herb, applied topically to the skin (in vivo), had an inhibitory effect on the lymphocytic reaction in the epidermis and the proliferation of local $T$ 
cells $[19,50]$. In clinical studies, the cream standardised to $1.5 \%$ hyperforin content improved skin condition and reduced skin colonization by Staphylococcus aureus in patients with mild to moderate atopic dermatitis clearly better than placebo [19].

A liquid extract of hyperici herba is used externally for treatment of minor cuts, burns and skin ulcers [51]. It is prepared by maceration of fresh flowering tops or dried herbal substance ( $1: 4$-20) in vegetable oil over a period from 2 days to several weeks under the sun light exposure, to be applied as compresses to affected areas. The use in children and adolescents under 18 years of age and longer than for 1 week (without consulting a doctor) is not recommended [50].

\section{Oenotherae oleum - evening primrose oil}

Oenothera biennis L. (evening primrose) is a plant that grows up to 1-2 $\mathrm{m}$ with a characteristic rosette of leaves close to the ground. The plant is infertile for the first year, and during its second year of life it produces bright yellow flowers and subsequently seeds containing up to $25 \%$ of fatty acids $[1,19]$. Active ingredients of evening primrose oil are triglycerides of fatty acids, mainly $\gamma$-linolenic and linoleic [52].

Oenothera oil is administered internally in treatment and alleviation of symptoms of atopic dermatitis. A clinical study of patients suffering from atopic dermatitis, in whom the influence of oenothera oil on inflammation, dryness, exfoliation and itch was estimated, revealed an improvement of all parameters in comparison to the placebo group. A positive correlation between the improvement of the above-mentioned parameters and the increase in the level of dihomo-gamma-linolenic acid (DGLA) which is formed from $\gamma$-linolenic acid (GLA) in human skin under the influence of the enzyme - elongase, was observed. DGLA and its metabolite 15-HETrE are among the epidermis lipids, including phospholipids and ceramides, which are essential for keeping the right structure and function of the epidermis barrier [13, 19, 53-55]. It was also proved that in patients with atopic dermatitis, disturbance of the GLA metabolic tract may lead to reduction of the synthesis of an important metabolite of this acid - prostaglandin $1\left(\mathrm{PGE}_{1}\right)$ - an anti-inflammatory compound [13]. Results of the study showing that atopic dermatitis develops in infants fed with milk with a low concentration of GLA and that supplementation of GLA can prevent development of atopic dermatitis in this population of patients, point indirectly to the GLA role in the treatment of atopic dermatitis [56, 57].

In a clinical study, patients were treated for symptomatic treatment of atopic eczema being administered 2-4 g fixed oil daily for 12 weeks. This study showed a 30-45\% improvement in the overall severity of the eczema, including a significant decrease of itching and scaling, as compared with patients who received the placebo. Topical application of Oleum Oenotherae Biennis for treatment of atopic eczema regulates the epidermal barrier function. A clinical study tested two doses of the fixed oil in the treatment of 51 children with atopic dermatitis. Patients were treated for 8 weeks with either a placebo, the fixed oil, or a combination of $50 \%$ placebo and $50 \%$ fixed oil (daily dose of $0.5 \mathrm{~g} / \mathrm{kg}$ body weight for all treatments). A significant improvement in the overall severity of the clinical symptoms was observed in patients treated with the fixed oil alone. This treatment also increased the concentration of $\omega 6$ fatty acids in the erythrocyte cell membranes [52].

Oleum Oenotherae Biennis should be used with caution in patients with a history of epilepsy and schizophrenia or those taking epileptogenic drugs. It should not be administered during pregnancy or lactation or to children without medical supervision [52].

\section{Quercus cortex - oak bark}

Trees of the Quercus genus are found only in the moderate zone of the northern hemisphere and in higher parts of the mountains of the tropical zone. English oak is the most popular representative of this genus [23].

Oak bark contains tannins. It has astringent and antiinflammatory properties. Pharmacological studies show effectiveness of oak bark in purulent dermatitis, and waterglycerolic extracts exhibit antibacterial activity against Staphylococcus sp. [1, 58, 59].

Oak bark is a traditional, herbal medicinal product for symptomatic treatment of minor inflammations of the skin, purulent skin diseases, exuding eczema and frostbite. Baths, topical rinses or poultices are used $[1,59]$. The use in children and adolescents under 18 years of age and longer than for 1 week is not recommended. Allergic reactions are reported [59].

\section{Juglandis folium - walnut leaf}

Juglans regia L. (walnut) is widely cultivated in Poland. It is a big, monoecious tree, with large, oval leaves, male flowers in the form of down-hanging catkin blossoms and female flowers located on tops of juvenile shoots, gathered in bunches [23].

Walnut displays astringent activity depending on the tannin content [60]. In vivo, ethanol extract of walnut leaves showed a potent anti-inflammatory activity, as potent as indomethacin, in the carrageenan-induced paw oedema in mice [61]. Walnut leaf is recommended for treatment of mild, superficial inflammations of the skin and excessive perspiration of hands and feet. In some countries it is used to treat dandruff and scalp itching, superficial burns and sunburns, and as itch-relieving treatment in skin disorders, and as a wash for malignant sores and pustules. An infusion of equal parts of walnut leaves and pansy is used externally for skin complaints in children.

It is used to prepare compresses and partial baths of affected areas of the skin. Occlusive dressings and topical 
applications to large areas are not recommended because of mutagenic and carcinogenic activity of juglone. For the same reason, the material is applied only externally [60].

\section{Lini semen - linseed}

Linum usitatissimum L. (flax) is cultivated all over the world. The material of commerce comes from Morocco, Argentina, Turkey and India. Characteristic small flowers with blue or white crown petals, located on tops of shoots, are gathered in bunches [62]. It contains fixed oil (consisting mainly of triglycerides of $\alpha$-linolenic and linoleic acids) and mucilage polysaccharides (neutral and acidic polysaccharides composed mainly of galacturonic acid). Flaxseed has anti-inflammatory, emollient and demulcent properties $[62,63]$. It is used for local inflammations of the skin and furunculosis as a warm poultice or compress [63].

\section{Trigonellae foenugraeci semen - fenugreek seed}

In nature, Trigonella foenum-graecum L (fenugreek) can be found in India, China and eastern Africa; it is grown in Poland. It has complex, triple leaves, seeds have a characteristic rhombic shape [23]. Fenugreek seed contains mucilage polysaccharides (galactomannan) and steroidal saponins (with aglycones: diosgenin, yamogenin, and tigogenin) [64]. The product is a traditional, herbal, medicinal product for use in specific indications, which is based exclusively upon its long-standing use in traditional medicine [65]. A fraction from methanolic extract of Trigonella foenum-graecum seed, containing glycoside and steroid derivatives, exhibited significant anti-inflammatory activity in the carrageenan-induced paw oedema in rats [66]. In traditional medicine, the fenugreek seed is used externally to treat furunculosis, eczema, ulcers, and local inflammations of the skin - as locally administered poultice or added to a hot bath $[64,67]$. The use in children and adolescents under 18 years of age is not recommended because of the incomplete data on safety [65].

\section{Conclusions}

Inflammation is a complex process, essential for the host defence system. Excessive production of some inflammatory mediators may lead to chronic diseases. Plant raw materials can have an anti-inflammatory action affecting various stages of the process of inflammation. They inhibit formation of cytokines and eicosanoids, prevent the inflammatory reaction cascade from starting, and diminish skin flare, itching or excessive exfoliation. The use of most of the presented herbal medicines in treatment of inflammatory skin diseases is based on clinical and pharmacological trials in vitro and experiments in vivo. But the use of some of them is based solely on their longstanding traditional use in folk medicine.

\section{References}

1. Weiss RF, Fintelmann V. Herbal medicine. Thieme, Stuttgart New York 2000; 293-314.

2. Ikeda Y, Murakami A, Ohigashi H. Ursolic acid: an anti- and pro-inflammatory triterpenoid. Mol Nutr Food Res 2008, 52: 26-42.

3. Karpel E. Systemic inflammatory response mediators - the importance in clinical practice and intensive care. Anest Inten Ter 2001; 3: 181-90.

4. Pharmacology - the fundamentals of pharmacotherapy and clinical pharmacology [Polish]. Kostowski W, Kubikowski B (eds). PZWL, Warsaw 1991; 121-2.

5. Aries MF, Vaissiere C, Fabre B, et al. Avena rhealba inhibits arachidonic acid cascade, CPLA2 and COX expression in human keratinocytes. Interest in cutaneous inflammatory disorders. J Invest Dermatol 2003; 121: JID abstract 0046.

6. EMEA. European Medicines Agency. Avena sativa L., Herba and Avena sativa L., Fructus. London 2008.

7. Tay YK, Kong KH, Khoo L, et al. The prevalence and descriptive epidemiology of atopic dermatitis in Singapore school children. Br J Dermatol 2002; 146: 101-6.

8. Teplitsky V, Mumcuoglu KY, Babai I, et al. House dust mites on skin, clothes, and bedding of atopic dermatitis patients. Int J Dermatol 2008; 47: 790-5.

9. Worm M. Novel therapies for atopic eczema. Curr Opin Investig Drugs 2002; 3: 1596-603.

10. Aries MF, Vaissiere C, Fabre B, et al. Immunomodulatory activity of Avena rhealba: interest in skin inflammatory disorders. J Invest Dermatol 1999; 113: 329.

11. Cosmetology and skin pharmacology [Polish]. Martini MC. PZWL, Warsaw 2007; 131-2.

12. Murata Y, Ogata J, Higaki Y, et al. Abnormal expression of sphingomyelin acylase in atopic dermatitis: an etiologic factor for ceramide deficiency? J Invest Dermatol 1996; 106: 1242-9.

13. Pytkowska K. Effect of lipids on epidermal barrier function. Wiadomości PTK 2003; 2: 7-10.

14. Schürer NY. Implementation of fatty acid carriers to skin irritation and epidermal barrier. Contact Dermatitis 2002; 47: 199-205.

15. ESCOP Monographs $2^{\text {nd }}$ ed. European Scientific Cooperative on Phytotherapy. Matricariae flos. Thieme, New York 2003; 312-9.

16. Ammon HPT, Sabieraj J, Kaul R. Kamille. Mechanismus der antiphlogistischen Wirkung von Kamillenextrakten und inhaltsstoffen. Deutsche Apotheker Zeitung 1996; 136: 17-25.

17. WHO Monographs on selected medicinal plants. Vol. 1. Flos Chamomillae. World Health Organization, Geneva 1999; 86-94.

18. Blumenthal M, Goldberg A, Brinckann J. Herbal medicine. Expanded Commission E Monographs. Chamomile flower, German. Newton, American Botanical Council 2000; 57-61.

19. Schulz V, Hänsel R, Blumenthal M, Tyler VE. Rational phytotherapy. Springer-Verlag, Berlin Heidelberg 2004; 335-47.

20. EMEA. European Medicines Agency. Calendula officinalis L., Flos. London 2008.

21. ESCOP Monographs $2^{\text {nd }}$ ed. European Scientific Cooperative on Phytotherapy. Calendulae flos. Thieme, New York 2003; 58-63.

22. WHO Monographs on selected medicinal plants. Vol. 2. Flos Calendulae. World Health Organization, Geneva 2002; 35-44.

23. Strzelecka H, Kowalski J. Encyclopedia of herbalism and phytotherapy [Polish]. PWN, Warsaw 2000; 42, 64, 124, 206-207, 252, 379, 397-398, 538-539. 
24. ESCOP Monographs $2^{\text {nd }}$ ed. European Scientific Cooperative on Phytotherapy. Hamamelidis cortex. Thieme, New York 2003; 226-9.

25. WHO Monographs on selected medicinal plants. Vol. 2. Folium et Cortex Hamamelidis. World Health Organization, Geneva 2002; 124-36.

26. EMEA. European Medicines Agency. Hamamelis virginiana L, Cortex Hamamelis virginiana L., Folium Hamamelis virginiana L., Folium Et Cortex aut Ramunculus Destillatum. London 2009

27. ESCOP Monographs $2^{\text {nd }}$ ed. European Scientific Cooperative on Phytotherapy. Hamamelidis folium. New York, Thieme 2003; 230-2.

28. ESCOP Monographs $2^{\text {nd }}$ ed. European Scientific Cooperative on Phytotherapy. Hamamelidis aqua. Thieme, Stuttgart-New York 2003; 223-5.

29. WHO Monographs on selected medicinal plants. Vol. 1. Aloe Vera Gel. World Health Organization, Geneva 1999; 43-9.

30. Choi S-W, Son B-W, Son Y-S, et al. The wound-healing effect of a glycoprotein fraction isolated from aloe vera. Br J Dermatol 2001; 145: 535-45.

31. Femenia A, Sánchez E, Simal S, Rossello C. Compositional features of polysaccharides from Aloe vera (Aloe barbadensis Miller) plant tissues. Carbohydr Polym 1999; 39: 109-17.

32. Choi SW, Chung MH. A review on the relationship between aloe vera components and their biologic effects. Semin Integr Med 2003; 1: 53-62.

33. Jia Y, Zhao G, Jia J. Preliminary evaluation: the effects of Aloe ferox Miller and Aloe arborescens Miller on wound healing. J Ethnopharmacol 2008; 120: 181-9.

34. ESCOP Monographs 2nd ed. European Scientific Cooperative on Phytotherapy. Altheae radix. Thieme, New York 2003; $32-5$.

35. WHO Monographs on selected medicinal plants. Vol. 2. Radix Althaeae, World Health Organization, Geneva 2002; 5-11.

36. Blumenthal M, Goldberg A, Brinckann J. Herbal medicine. Expanded Commission E Monographs. Marshmallow root. Newton, American Botanical Council 2000; 246-7.

37. Blumenthal M, Goldberg A, Brinckann J. Herbal medicine. Expanded Commission E Monographs. Oat straw. Newton, American Botanical Council 2000; 281-2.

38. EMEA. European Medicines Agency Echinacea purpurea (L.). Moench, Herba Recens, London 2008.

39. ESCOP Monographs $2^{\text {nd }}$ ed. European Scientific Cooperative on Phytotherapy. Echinaceae purpureae herba. Thieme, New York Supplement 2009; 91-101.

40. Rininger JA, Kickner S, Chigurupati P, et al. Immunopharmacological activity of Echinacea preparations following simulated digestion on murine macrophages and human peripheral blood mononuclear cells. J Leukoc Biol 2000; 68: 503-10.

41. WHO Monographs on selected medicinal plants. Vol. 1. Herba Echinaceae Purpureae. World Health Organization, Geneva 1999; 136-44.

42. ESCOP Monographs $2^{\text {nd }}$ ed. European Scientific Cooperative on Phytotherapy. Symphyti radix. Thieme, New York, Supplement 2009; 249-54.

43. Blumenthal M, Goldberg A, Brinckann J. Herbal medicine. Expanded Commission E Monographs. Yarrow. Newton, American Botanical Council 2000; 419-23.

44. ESCOP Monographs $2^{\text {nd }}$ ed European Scientific Cooperative on Phytotherapy. Millefolii herba. Thieme, New York Supplement 2009; 175-83.

45. Blumenthal M, Goldberg A, Brinckann J. Herbal medicine. Expanded Commission E Monographs. Plantain. Newton, American Botanical Council 2000; 307-10.
46. ESCOP Monographs $2^{\text {nd }}$ ed. European Scientific Cooperative on Phytotherapy. Plantaginis lanceolatae folium/herba. Thieme, New York 2003; 383-7.

47. Blumenthal M, Goldberg A, Brinckann J. Herbal medicine. Expanded Commission E Monographs. Sage leaf. Newton, American Botanical Council 2000; 330-3.

48. EMEA. European Medicines Agency. Salvia officinalis L., Folium and Salvia officinalis L., Aetheroleum, London 2009.

49. ESCOP Monographs $2^{\text {nd }}$ ed. European Scientific Cooperative on Phytotherapy. Salviae officinalis folium. Thieme, New York 2003; 452-5.

50. EMEA. European Medicines Agency. Hypericum perforatum L, Herba. London 2008.

51. WHO Monographs on selected medicinal plants. Vol. 2. Herba Hyperici. World Health Organization, Geneva 2002; 149-71.

52. WHO Monographs on selected medicinal plants. Vol. 2. Oleum Oenotherae Biennis. World Health Organization, Geneva 2002; 217-30.

53. Arct J, Pytkowska K. The biologically active lipids and their derivatives in cosmetics. Wiadomości PTK 2003; 1: 8-11.

54. Chung S, Kong S, Seong K, Cho Y. Gamma-linolenic acid in borage oil reverses epidermal hyperproliferation in guinea pigs. J Nutr 2002; 132: 3090-7.

55. van Gool CJ, Zeegers MP, Thijs C. Oral essential fatty acid supplementation in atopic dermatitis - a meta-analysis of placebo-controlled trials. Br J Dermatol 2004; 150: 728-40.

56. Laitinen K, Sallinen J, Linderborg K, Isolauri E. Serum, cheek cell and breast milk fatty acid compositions in infants with atopic and non-atopic eczema. Clin Exp Allergy 2006; 36: 166-73.

57. van Gool CJ, Thijs C, Henquet CJ, et al. Gamma-linolenic acid supplementation for prophylaxis of atopic dermatitis - a randomized controlled trial in infants at high familial risk. Am J Clin Nut 2003; 77: 943-51.

58. Blumenthal M, Goldberg A, Brinckann J. Herbal medicine. Expanded Commission E Monographs. Oak bark. Newton, American Botanical Council 2000; 278-80.

59. EMEA. European Medicines Agency. Quercus Robur L., Quercus Petraea (Matt.) Liebl. and Quercus Pubescens Willd., Cortex. London 2010.

60. Blumenthal M, Goldberg A, Brinckann J. Herbal medicine. Expanded Commission E Monographs. Walnut leaf. Newton, American Botanical Council 2000; 401-3.

61. Erdemoglu N, Küpeli E, Yeşilada E. Anti-inflammatory and antinociceptive activity assessment of plants used as remedy in Turkish folk medicine. J Ethnopharmacol 2003; 89: 123-9.

62. Blumenthal M, Goldberg A, Brinckann J. Herbal medicine. Expanded Commission E Monographs. Flaxseed. Newton, American Botanical Council 2000; 134-5.

63. ESCOP Monographs $2^{\text {nd }}$ ed. European Scientific Cooperative on Phytotherapy. Lini semen. Thieme, New York 2003; 290-6.

64. ESCOP Monographs $2^{\text {nd }}$ ed. European Scientific Cooperative on Phytotherapy. Trigonellae foenugraeci semen. Thieme, New York 2003; 511-20.

65. EMEA. European Medicines Agency. Trigonella foenum-graecum L., Semen, London 2010.

66. Vyas S, Agrawal R, Solanki P, Trivedi P. Analgesic and antiinflammatory activities of Trigonella foenum-graecum (seed) extract. Acta Pol Pharm - Drug Research 2008; 65: 473-6.

67. WHO Monographs on selected medicinal plants. Vol. 3. Semen Trigonellae Foenugraeci. World Health Organization, Geneva 2007; 247-56. 